\title{
The inhibitory activity of cocoa phenolic extract against pro-inflammatory mediators secretion induced by lipopolysaccharide in RAW 264.7 cells
}

\author{
Yazan Ranneh ${ }^{1}$, Faisal Ali ${ }^{1,2}$, Mothanna Al-Qubaisi ${ }^{3}$, Norhaizan Mohd Esa ${ }^{1,3^{*}}$ and Amin Ismail ${ }^{1}$
}

\begin{abstract}
Cocoa is a rich source of polyphenols that has been traditionally used as the treatment of several types of inflammation related disease. The response to inflammation comprises the consecutive release of mediators and the enlistment of circulating leukocytes, such as macrophages. Currently, Cocoa-derived polyphenolics have shown antiinflammatory effects in vivo, but the therapeutic benefits in vitro remain unclear. Therefore, in this study, the effect of cocoa polyphenolic extract (CPE) on RAW 264.7 macrophage cells sensitized by lipopolysaccharide as in vitro inflammatory model was investigated. The anti-inflammatory activity of CPE was assessed by measuring its ability to inhibit the pro-inflammatory enzyme 5-lipoxygenase (5-LOX) and the pro-inflammatory mediators prostaglandin $\mathrm{E}_{2}\left(\mathrm{PGE}_{2}\right)$, reactive oxygen species (ROS), nitric oxide (NO) and tumor necrosis factor-alpha (TNF-a). The results show that CPE significantly inhibits 5-LOX activity $(p<0.01)$. In addition, CPE dose-dependently suppressed the production of PGE ${ }_{2}$, ROS, NO and TNF-a in RAW 264.7 cells. These data suggest that CPE may be used for the treatment of inflammation and it's related-diseases.
\end{abstract}

Keywords: Cocoa, Polyphenols treatment, Inflammation, 5-Lipoxygenase, Prostaglandin, RAW 264.7 macrophage cells

\section{Background}

Reactive oxygen species (ROS) are naturally and continuously produced as a result of cellular metabolism in all aerobic organisms. Many studies have indicated the deleterious effect of ROS in deteriorating health (Datta et al. 2000; Ali et al. 2013). In addition, a wide range of diseases associated with inflammation are correlated with a high production of ROS (Reuter et al. 2010). During inflammation, respiratory bursts produced by inflammatory cells lead to the increased production and accumulation of ROS at the site of damage (Hussain et al. 2003). Conversely, mitochondrial ROS inhibitors reduce the production of

\footnotetext{
*Correspondence: nhaizan@upm.edu.my

${ }^{1}$ Department of Nutrition and Dietetics, Faculty of Medicine and Health Sciences, Universiti Putra Malaysia (UPM), 43400 Serdang, Selangor, Malaysia

Full list of author information is available at the end of the article
}

lipopolysaccharide (LPS)-induced IL-6, suggesting the existence of other inhibitions for inflammatory mediators (Edwina and Vishva 2013; Naik and Dixit 2011).

The response to inflammation comprises the consecutive release of mediators and the enlistment of circulating leukocytes, such as macrophages, that become stimulated at the area of inflammation, thereby releasing various types of mediators and cytokines with either pro- or anti-inflammatory actions, such as IL-1 $\beta$, IL-6, NO, TNF- $\alpha$ and PG (Day 2002; Feldmann et al. 1996). These inflammatory mediators have either pro- or anti- inflammatory actions (Bessis and Boissier 2001). Cytokines incite the chemotactic efflux of monocytes, granulocytes, mast cells and lymphocytes to tissues to support antigen elimination and tissue revival (Eigler et al. 1997; Ershler and Keller 2000). Excessive leakage and stimulation of cells induce tissue damage, resulting in pain and edema 
(vascular perfusion), which are similar in appearance to inflammation.

TNF- $\alpha$ is an essential factor for the stimulation of the genetic expression of inducible nitric oxide synthase (iNOS) in various cells lines (Wolf et al. 2005). In addition, iNOS is extremely important in macrophages, where its activation results in nitric oxide production (Mac Micking et al. 1997; Vane et al. 1994; Adams et al. 2002), that not only causes organ devastation in some autoimmune and inflammatory diseases but also adjusts various physiological mechanisms, such as vasodilatation (Marletta et al. 1998; Moncada et al. 1991).

During inflammation, the production of fatty acids, including arachidonic acid, which is the main harbinger of fatty acid metabolites, is considerably increased (Kuehl and Egan 1980). Arachidonic acid is first secreted from the cellular membrane by phospholipase enzymes (Burdan et al. 2006) and then transformed by either cyclooxygenase (COX-2) to prostaglandins (PGs) (Pang and Hoult 1997), or by lipoxygenase (LOX) to leukotrienes (LT) (Khanapure et al. 2007). Excessive PGE $_{2}$ produced by COX-2 induces various inflammatory cytokines. On the other hand, the 5-LOX-catalyzed production of LT from plaque cells has been demonstrated to support the inflammatory state in endothelial cells through the flux of leukocytes and the vasoconstriction of arteries (Back 2008).

Because NO, LT and $\mathrm{PGE}_{2}$ are the main factors promoting inflammation and pain, the inhibition of the biosynthesis of these inflammatory intermediaries by blocking the TNF- $\alpha-\mathrm{NO}, \mathrm{PGE}_{2}$-COX2 and 5-LOX-LT pathways, which are the primary pathways responsible for their inflammatory action, is hypothesized to be a promising approach for reducing undesired inflammatory effects. Although corticosteroids and non-steroidal anti-inflammatory drugs (NSAIDs) exert an inhibitory effect on these pathways (Hunskaar and Hole 1987), most NSAIDs exhibit an unwanted side effect on the central nervous, renal, coagulation, cardiovascular and immune systems and the gastrointestinal tract (Rainsford 1999; Mukherjee et al. 2001). Thus, it is very important to decrease the side effects of inflammatory medications by using a different drug or administering the medication in combination with natural products, such as cocoa.

Cocoa is a product of the seeds of the cacao tree (Theobroma cacao L.), which is native to the low Andean foothills and the Amazon and Orinoco River basins. It is interesting to note that theobroma means "food of the gods," as translated from Greek (Keen 2001). Cocoa has been applied for therapeutic purposes to cure several disorders, such as fever, indigestion, angina and heart, liver and lung diseases (Keen 2001; Seligson et al. 1994). Polyphenols, which are widely found in plants, are the primary antioxidative component of cocoa and can be classified into various subclasses, such as flavanols and procyanidins. The intake of chocolate rich in flavonoids by individuals demonstrated a significant decrease in the plasma level of cysteine leukotrienes and prostacyclin (prostaglandin $I_{2}$ ) (Schramm et al. 2001). As reported by previous studies, cocoa polyphenols exhibit potential health benefits for several chronic diseases, including cardiovascular illness, neurodegenerative disorders and prostate cancer (Kurosawa et al. 2005; Bisson et al. 2008). Many studies on the anti-inflammatory efficacy of cocoa has extensively investigated in vivo (Mukherjee et al. 2001; Kurosawa et al. 2005; Sies et al. 2005; Ono et al. 2003). To the best of our knowledge, few studies have investigated the effect of the cocoa polyphenolic extract $(\mathrm{CPE})$ on $\mathrm{PGE}_{2}$ and 5-LOX and the available information on this effect is limited. To close this gap, the aims of the current study were to (a) determine the influence of CPE on 5-LOX and $\mathrm{PGE}_{2}$ and (b) investigate the effect of CPE on the production of ROS, TNF- $\alpha$ and NO. To illustrate the mechanism of action of CPE, LPS-sensitized RAW 264.7 macrophages were used to analyze the production of ROS, NO, $\mathrm{PGE}_{2}$, TNF- $\alpha$ and 5-LOX using a synthetic substrate (soybean lipoxygenase).

\section{Methods}

Preparation of cocoa polyphenolic extracts (CPE)

Malaysian cocoa powder was kindly gifted by KL-Kepong Cocoa Products Sdn. Bhd. (Port Klang, Selangor, Malaysia). The cocoa extract was prepared following the method described by (Ruzaidi et al. (2005). Briefly, the defatted powder was treated with $80 \%(\mathrm{v} / \mathrm{v})$ ethanol for $2 \mathrm{~h}$. The ethanol was removed using a rotary evaporator (Buchi Rotavor R-200, Flawil, Switzerland) at $55{ }^{\circ} \mathrm{C}$ for $45 \mathrm{~min}$. The resulting extract was lyophilized through freeze-drying (The Virtis Company Inc., Gardiner, NY, USA) at $45^{\circ} \mathrm{C}$ and 120 bar.

\section{Phenol and flavonoid contents CPE}

The total amounts of phenols and flavonoids were measured following the method described by Schinella et al. 2010. The total phenol content was determined using the Folin-Ciocalteu reagent and gallic acid as the standard and is expressed as mg of gallic acid equivalent $(\mathrm{GAE}) / 100 \mathrm{ml}$ of extract. The total flavonoid content was measured in a $10 \% \mathrm{AlCl}_{3} \cdot 3 \mathrm{H}_{2} \mathrm{O}$ solution using (+)-catechin as the standard and is expressed as $\mathrm{mg}$ of catechin equivalent (CE)/100 $\mathrm{ml}$ of extract. 


\section{Cell culture}

The murine monocytic macrophage-like cell line RAW 264.7 from the American Type Cell Culture Collection (Manassas, VA, USA) was cultured in Dulbecco's modified Eagle's medium (DMEM) supplemented with $2 \mathrm{mM}$ glutamine, 100 units $/ \mathrm{ml}$ penicillin, $100 \mu \mathrm{g} / \mathrm{ml}$ streptomycin, $10 \mathrm{mM}$ 4-[2-hydroxyethyl]-1-piperazineethanesulfonic acid (HEPES) and $10 \%$ fetal bovine serum (FBS) and incubated at $37{ }^{\circ} \mathrm{C}$ in a $5 \% \mathrm{CO}_{2}$ atmosphere. After reaching 80-90\% confluence, the RAW 264.7 cells were removed, trypsinized and centrifuged at $120 \times g$ and $4{ }^{\circ} \mathrm{C}$ for $10 \mathrm{~min}$. The cells were then treated with serial concentrations of CPE from 15.63 to $1000 \mu \mathrm{g} / \mathrm{ml}$ and $10 \mu \mathrm{g} /$ $\mathrm{ml}$ lipopolysaccharide (LPS).

\section{Cell viability by MTT assay}

The cytotoxicity of CPE on seeded RAW 264.7 cells was evaluated by measuring the formation of formazan salts due to the reduction of 3-(4,5-dimethylthiazol-2-yl)2,5-diphenyl tetrazolium bromide (MTT). The cells were cultured for $18 \mathrm{~h}$ and then treated with LPS $(10 \mu \mathrm{g} / \mathrm{ml})$ and serial concentrations of CPE for $24 \mathrm{~h}$. Then, $20 \mu \mathrm{l}$ of $5 \mathrm{mg} / \mathrm{ml} \mathrm{MTT}$ was added to each well and the wells were incubated for $4 \mathrm{~h}$ at $37{ }^{\circ} \mathrm{C}$. The formazan crystals were then dissolved by the addition of $200 \mu \mathrm{l}$ of dimethyl sulfoxide (DMSO) at $37{ }^{\circ} \mathrm{C}$ for $30 \mathrm{~min}$. The optical density of the wells was read at $570 \mathrm{~nm}$ using a microplate reader (Molecular Devices Inc., Sunnyvale, CA, USA). The rate of cell death was specified relative to that of the control group.

\section{Quantification of reactive oxygen species}

The ROS formation was quantified by measuring the conversion of $2^{\prime} 7^{\prime}$-dichlorofluresceine diacetate (DCFH-DA) to dichlorofluoresceine (DCF) through ROS oxidation (LeBel et al. 1990). At $80 \%$ confluence, RAW macrophage cells were treated with serial concentrations of CPE and $10 \mu \mathrm{M} \mathrm{H}_{2} \mathrm{O}_{2}$ for $24 \mathrm{~h}$. The treated cells were washed with PBS and incubated with $2^{\prime}, 7^{\prime}$-dichlorofluorescein diacetate (DCFH-DA) for $15 \mathrm{~min}$ in the dark at $37{ }^{\circ} \mathrm{C}$. After washing, the cells were lysed in buffer $(50 \mathrm{mM}$ Tris- $\mathrm{HCl}$, $100 \mathrm{mM} \mathrm{NaCl}, 1 \mathrm{mM} \mathrm{CaCl}, 1 \mathrm{mM} \mathrm{MgCl}, 300 \mathrm{mM}$ sucrose, $1 \%$ Triton $\mathrm{X}-100, \mathrm{pH} 7.4$ ) and the fluorescence of the lysates was measured at $529 \mathrm{~nm}$ with an excitation wavelength of $495 \mathrm{~nm}$ in a stirred quartz cuvette. The DCF fluorescence density is proportional to the amount of intracellular ROS.

\section{Quantification of nitric oxide (NO)}

The RAW 264.7 cells were cultured in 96-well plates $\left(1 \times 10^{6}\right.$ cells $\left./ 100 \mathrm{ml}\right)$ for $24 \mathrm{~h}$ at $37{ }^{\circ} \mathrm{C}$ in a $5 \% \mathrm{CO}_{2}$ atmosphere. Then, $1000 \mu \mathrm{g} / \mathrm{ml} \mathrm{CPE}$ was diluted and added to the well to obtain final concentrations of 500 , 250, 125, 62.5, 31 and $15.6 \mu \mathrm{g} / \mathrm{ml}$. The cells were then sensitized with $200 \mathrm{U} / \mathrm{ml}$ interferon-gamma (IFN- $\gamma$ ) and $10 \mu \mathrm{g} / \mathrm{ml}$ LPS for $20 \mathrm{~h}$. The quantity of nitrite, which is a steadily oxidized product of $\mathrm{NO}$, was measured in tissue culture media using the Griess reagent $[1 \%(\mathrm{w} / \mathrm{v})$ sulfonamide and $0.1 \%(\mathrm{w} / \mathrm{v}) \mathrm{N}$-(1-naphtyl)ethylenediamine dihydrochloride in $2.5 \%(\mathrm{v} / \mathrm{v})$ phosphoric acid]. To summarize, $100 \mathrm{ml}$ of the cell culture fluid was combined with $100 \mu \mathrm{l}$ of the Griess reagent in a 96-well plate and the absorbance was then read spectrophotometrically using a microplate reader at $540 \mathrm{~nm}$. Dilutions of sodium nitrite were used to obtain a standard curve to determine the amount of nitrite in each sample (Di et al. 1996).

\section{Quantification of lipoxygenase}

$\mathrm{CPE}$ at different concentrations ranging from 1000 to $15.625 \mu \mathrm{g} / \mathrm{ml}$ was prepared in DMSO. Sodium phosphate buffer $(160 \mu \mathrm{l}, 0.05 \mathrm{M}, \mathrm{pH} 7.5), 10 \mu \mathrm{l}$ of the test solution and $20 \mu \mathrm{l}$ of linoleic acid solution were mixed and incubated for $10 \mathrm{~min}$ at $25^{\circ} \mathrm{C}$. The reaction was then initiated by the addition of $10 \mu \mathrm{l}$ of the substrate in the form of soybean lipoxygenase solution. The enzymatic conversion of sodium linoleic acid to (9Z,11E)- (13S)-13-hydroperoxyoctadeca-9,11-dienoate was measured by monitoring the change in the absorbance at $295 \mathrm{~nm}$ over a period of 6 min using a spectrophotometer. Nordihydroguaiaretic acid (NDGA) was used as the positive control in this assay. All of the tests were performed in triplicate in a 96-well UV microplate (Frum and Viljoen 2006).

\section{$\mathrm{PGE}_{2}$ and TNF- $\alpha$ assay}

The PGE 2 and TNF- $\alpha$ level in the RAW macrophage culture medium were quantified using ELISA kits according to the manufacturer's instructions (Sigma-Aldrich). The production of $\mathrm{PGE}_{2}$ and $\mathrm{TNF}-\alpha$ was measured relative to that of the control. All of the experiments were performed in triplicate.

\section{Data analysis}

The values are presented as the means of three replicate determinations \pm the standard error of the mean $( \pm \mathrm{SEM})$. All of the data were subjected to one-way analysis of variance (ANOVA) to test whether there are significant differences in the anti-inflammatory activity of CPE and the significance of the difference between the means was determined using Duncan's multiple-range test $(p<0.05)$. The data analyses were performed using SPSS for Windows (version 18.0). 


\section{Results}

\section{Phenol and flavonoid contents}

The total phenols and flavonoid contents in the CPE are presented in Table 1 . The concentration of phenolic acids $(114 \mathrm{mg} / \mathrm{g})$ in the CPE was higher than the flavonoid concentration $(94.95 \mathrm{mg} / \mathrm{g})$.

\section{Viability of RAW 264.7 cells}

To confirm the nontoxic effect of CPE on RAW 264.7 cells, the viability of the cells was examined using the MTT assay. As shown in Fig. 1, the treatment of LPSstimulated cells with CPE at a concentration up to $1000 \mu \mathrm{g} / \mathrm{ml}$ did not affect the viability of the cells compared with untreated LPS-stimulated cells. The highest inhibition rate was approximately $20 \%$.

\section{Inhibitory effect of CPE on ROS formation}

To investigate whether CPE can inhibit intracellular ROS, RAW 264.7 macrophage cells were treated with varying concentrations of $\mathrm{CPE}$ and then exposed to $\mathrm{H}_{2} \mathrm{O}_{2}$. A fluorescence protocol based on $2^{\prime} 7^{\prime}$-dichlorofluresceine diacetate (DCFH-DA) was used to measure the intracellular ROS. CPE significantly $(p<0.01)$ suppressed the $\mathrm{H}_{2} \mathrm{O}_{2}$-induced intracellular ROS accumulation in a dosedependent manner compared with the untreated cells (Fig. 2).

\section{Inhibitory effect of CPE on Nitric oxide}

As described below, LPS stimulation caused a significant production of $\mathrm{NO}$ in the culture medium. However, the pretreatment of the cells with CPE at different concentrations significantly inhibited the LPS-induced nitrite accumulation in a dose-dependent manner (Fig. 3).

\section{Inhibitory effect of CPE on 5-lipoxygenase}

Similarly to previous studies on purified enzymes, CPE was found to potently affect the activity of purified 5-LOX. The enzyme inhibition by CPE was concentration-dependent at concentrations ranging from 15.63 to $1000 \mu \mathrm{g} / \mathrm{ml}$ with an $\mathrm{IC}_{50}$ value of $155 \mu \mathrm{g} / \mathrm{ml}$ (Fig. 4). NDGA, which was used as a positive control, gave an $\mathrm{IC}_{50}$ value of $4 \mu \mathrm{g} / \mathrm{ml}$ (Fig. 5).

\section{Table 1 Contents of flavonoids and phenolic acids in CPE}

\begin{tabular}{ll}
\hline Phenolic acid amount & $114 \mathrm{mg} / \mathrm{g}$ \\
Flavonoid amount & $94 \mathrm{mg} / \mathrm{g}$ \\
Yield extract $^{\mathrm{a}}$ & $23 \mathrm{~g} / 100 \mathrm{~g}$ \\
\hline
\end{tabular}

${ }^{\mathrm{a}}$ Yield $($ percent $)=[$ solvent extracts wt $(\mathrm{g}) /$ sample wt $(\mathrm{g})] \times 100$
Inhibitory effect of CPE on LPS-induced PGE $_{2}$ and TNF- $a$ production

Because $\mathrm{PGE}_{2}$ and TNF- $\alpha$ are inflammatory mediators, the effects of CPE on $\mathrm{PGE}_{2}$ and TNF- $\alpha$ production in LPS-stimulated RAW 264.7 cells were also measured (Table 2). The incubation of the cells with serial concentrations of CPE prior to LPS treatment caused a significant dose-dependent decrease $(p<0.05$ or $p<0.01)$ in the production of $\mathrm{PGE}_{2}$ and

\section{TNF- $a$ compared with the untreated LPS-stimulated cells} (Figs. 6, 7)

\section{Discussion}

Natural products have played a significant role not only in clinical nutrition against several diseases but also in drug discovery and development by contributing to the discovery of alternative therapies. In addition, the active participation of macrophages in the inflammatory response by the secretion of mediators induced by pathogenic-derived factors, such as LPS and IFN- $\gamma$, contributes to the establishment of in vitro inflammatory models (Zhang et al. 2010; Yoon et al. 2009). In the current study, the ethanolic polyphenol extract from cocoa (CPE) was prepared and its effects on the LPS-induced inflammation in a murine macrophage cell line (RAW 264.7) were examined. The cytotoxicity of CPE in RAW 264.7 cells was also assessed using the MTT assay. The findings showed that CPE does not influence the viability of RAW 264.7 cells.

An active stimulant to inflammation is ROS and it has been noted that the ability of macrophages to produce ROS depends on the level of tissue damage. It is noteworthy that the chemotactic factors released from inflammatory cells may accumulate and induce the release of ROS. In the current study, CPE was found to significantly inhibit ROS with an $\mathrm{IC}_{50}$ value of $425.95 \mu \mathrm{g} / \mathrm{ml}$. These results are consistent with those reported by RodriguezRamiro et al. (2011) who showed the inhibition of ROS production in the Caco-2 cell line by procyanidin B2 and CPE. In contrast, Chai et al. (2003) showed the production of a high concentration of ROS in cell cultures incubated with epigallocatechin gallate (EGCG) derived from wine and green tea.

Of the many inflammatory mediators that can stimulate vascular permeability, it is well documented that $\mathrm{NO}, \mathrm{PGE}_{2}$ and LT are the primary factors implicated in the pathogenic process of several inflammatory diseases (Salmon and Higgs 2012; Bi et al. 2005), iNOS, which is expressed and activated in different cell types through stimulation with TNF- $\alpha$ and/or LPS, has the 

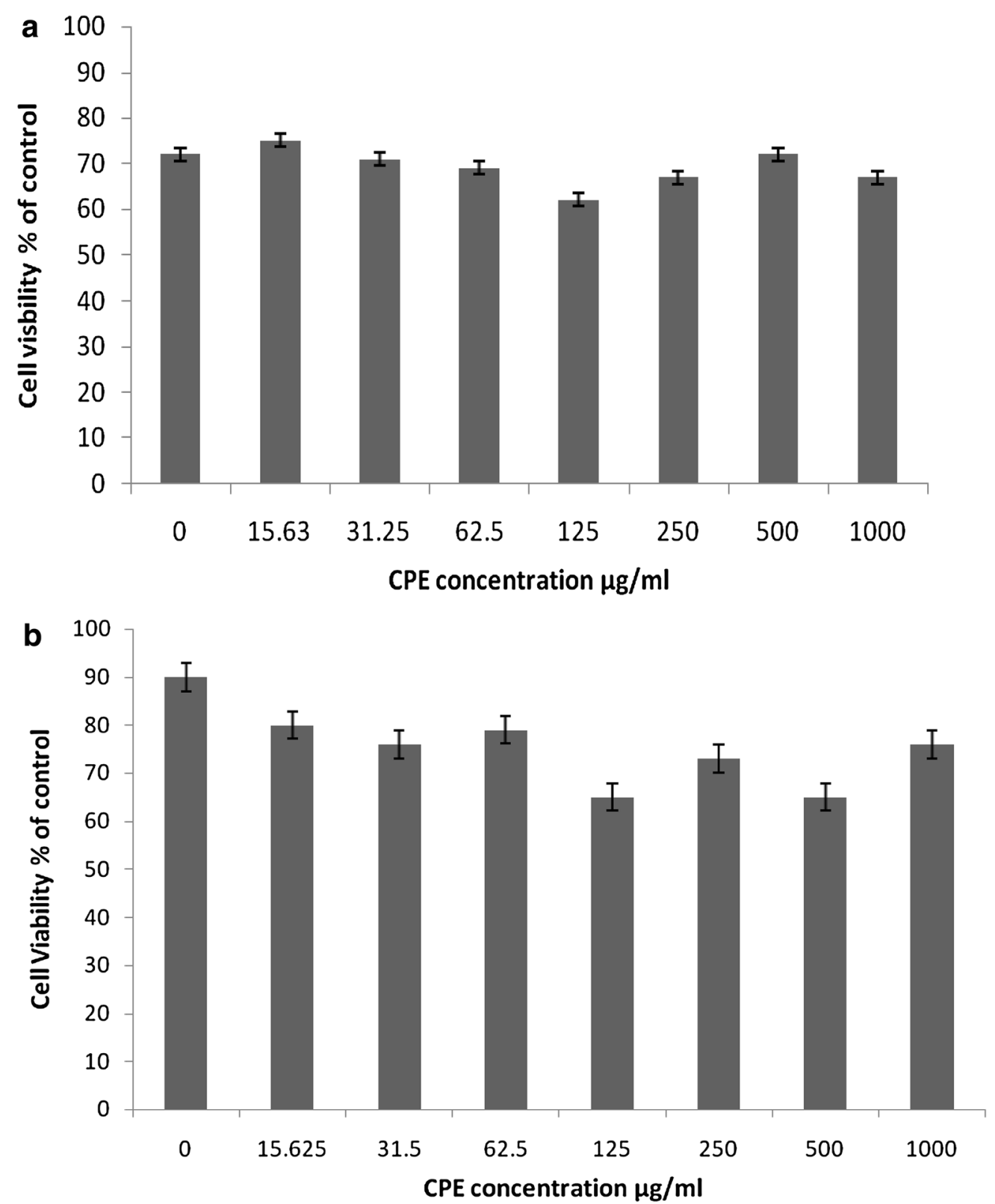

Fig. 1 a Cell viability of cells treated with various concentrations of CPE and LPS for $24 \mathrm{~h}$. The cell viability was determined by the MTT assay as described in "Methods" section. The results are expressed as the mean \pm SEM $(n=3)$. b Cell viability of cells treated with various concentrations of CPE only for $24 \mathrm{~h}$. The cell viability was determined by the MTT assay as described in in "Methods" section. The results are expressed as the mean $\pm \operatorname{SEM}(n=3)$

ability to increase the NO concentration (Mac Micking et al. 1997). Under specific conditions, the treatment of stimulated RAW 264.7 cells with CPE results in a considerable inhibition of NO production. However, the mechanism responsible for the downregulation of NO production by polyphenols and flavonoids has not been fully elucidated. It has been reported that this effect is most likely due to the integration of multiple different bioactivities, such as the suppression of the activity of the iNOS enzyme, the scavenging activity of NO and the suppression of the mRNA expression of iNOS (Moncada et al. 1991). In addition, TNF- $\alpha$ is released in small quantities under normal condition, but this amount increases during the inflammatory 


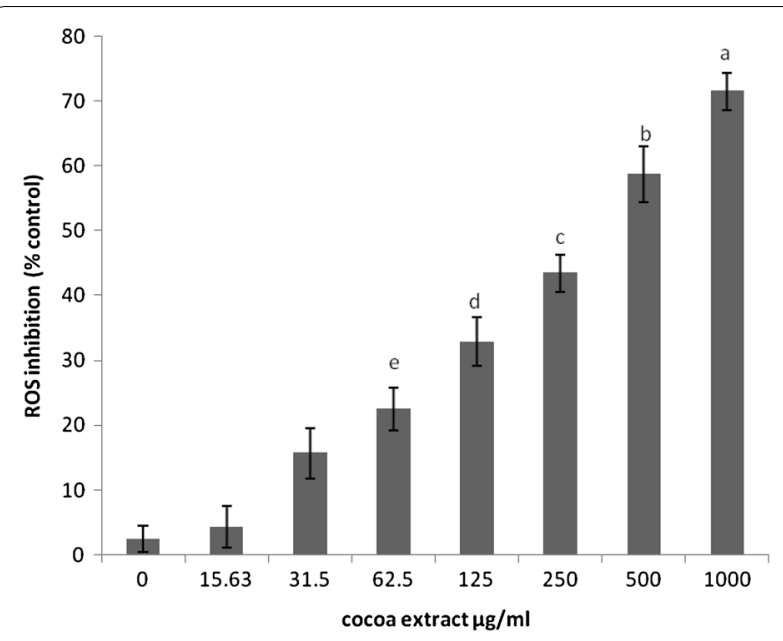

Fig. 2 Inhibition of ROS in RAW 264.7 cell cultures treated with CPE for $24 \mathrm{~h}$. The results are expressed as the mean $\pm \operatorname{SEM}(n=3)$. The means with different letters were significantly different $(p<0.01)$

state stimulated by LPS in macrophages. Cells treated with different concentrations of CPE showed a significant inhibition of TNF- $\alpha$ production (Fig. 6; Table 1). Moreover, the TNF- $\alpha-\mathrm{NO}$ pathway has been found to be inhibited by iNOS inhibitors (corticosteroids) (Wolf et al. 2005). Similarly, Bi et al. (2005) and Park et al. (2000) also reported that flavonoids and resveratrol exert inhibitory effects on NO and TNF- $\alpha$ in an in vitro model.

More importantly, the repression of the biogenesis of inflammatory mediators, particularly $\mathrm{PGE}_{2}$ and LT, is considered a promising method for the management of different types of diseases associated with inflammation, such as osteoarthritis (Celotti and Laufer 2001). Recent studies discuss 'dual inhibitors', which are agents that have the capability to suppress not only COX-1 and COX-2 but also 5-LOX (Brune 2004). Our experiments revealed the inhibitory activity of $\mathrm{CPE}$ on the production of $\mathrm{PGE}_{2}$ and 5-LOX (Figs. 4, 5; Table 1) by targeting the COX-PGE 2 and 5-LOX-LT pathways. Consistent with the findings reported by Altavilla et al. (2009) we found that flavonoids have a suppressive effect on the production of $\mathrm{PGE}_{2}$ and LT. Additionally, sinapic acid, one of the polyphenol components, has been shown to inhibit COX-2 in RAW macrophage cells (Yun et al. 2008). It should be noted that, the different polyphenols exert different effects on pro-inflammatory mediators; some polyphenols suppress pro-inflammatory mediators whereas others can induce the production of these mediators. Surprisingly, the highest $\mathrm{IC}_{50}$ value found for these mediators was related to ROS and this value suggested a suitable inhibitory concentration.

\section{Conclusion}

Our results support the findings of previous reports on the anti-inflammatory activity of cocoa and its by-products. However, a direct comparison cannot be established with other compounds mentioned in the literature due to differences in the experimental assays. The current results strengthen the underlying evidence of the protective effect of CPE against the

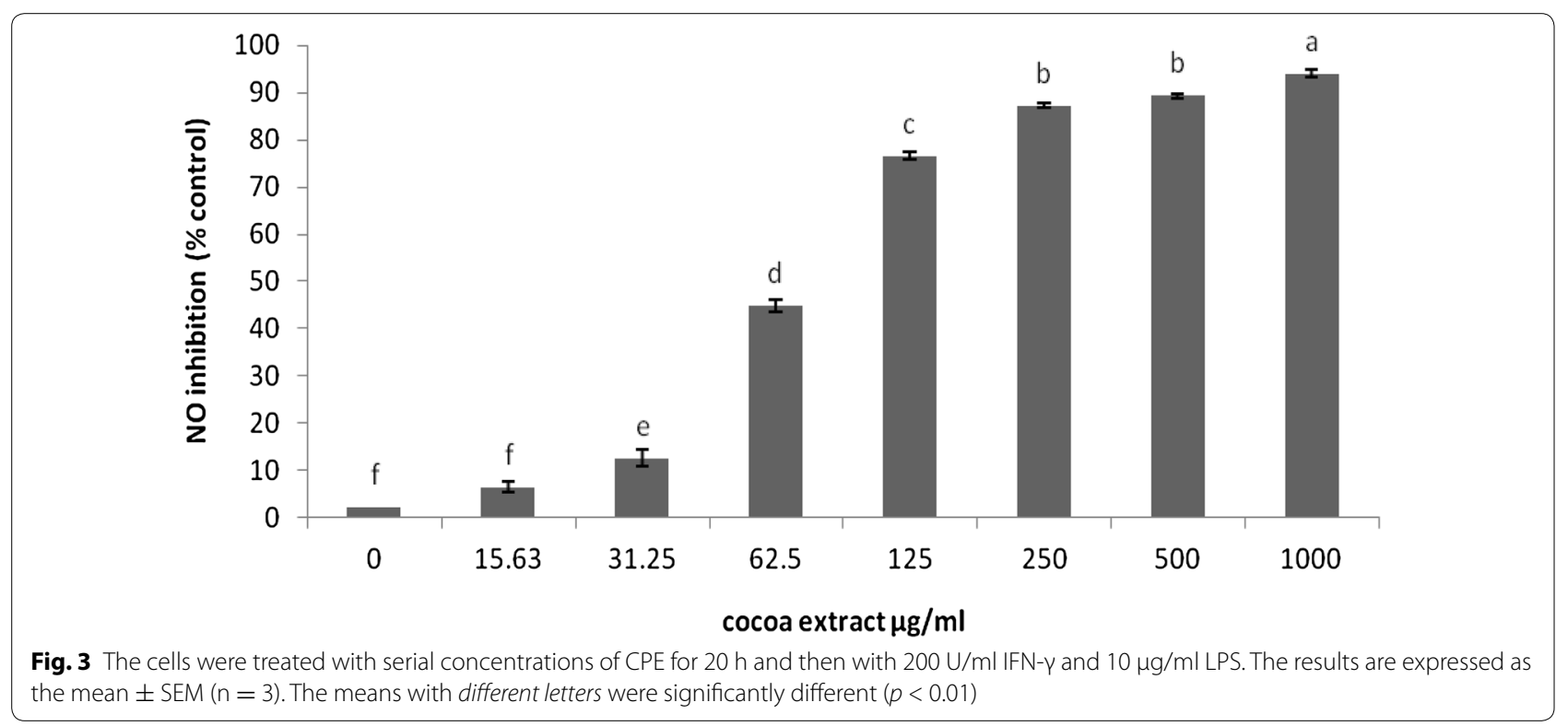




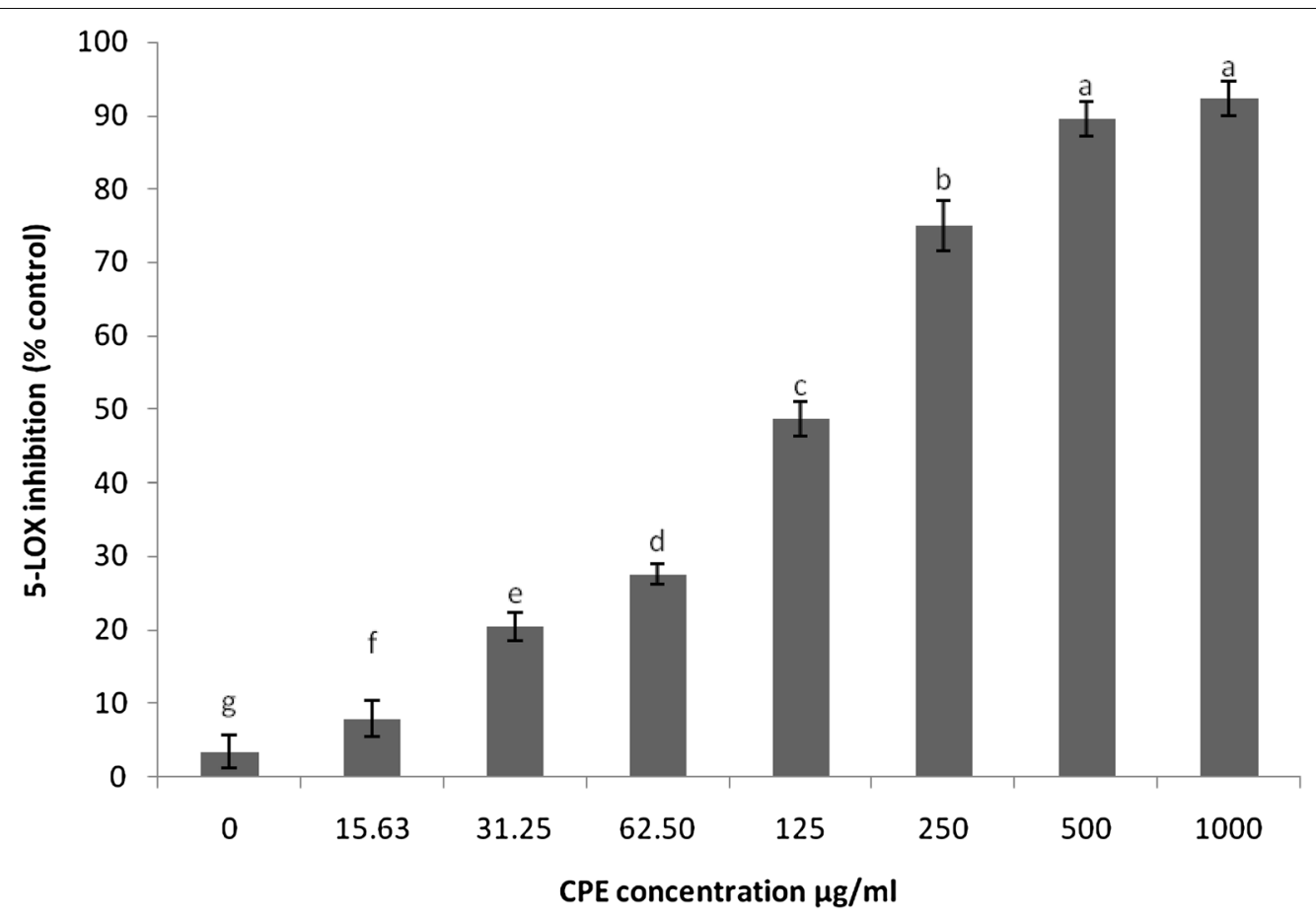

Fig. 4 Inhibition of soybean 5-LOX by CPE. The results are expressed as the mean \pm SEM $(n=3)$. The means with different letters were significantly different $(p<0.01)$

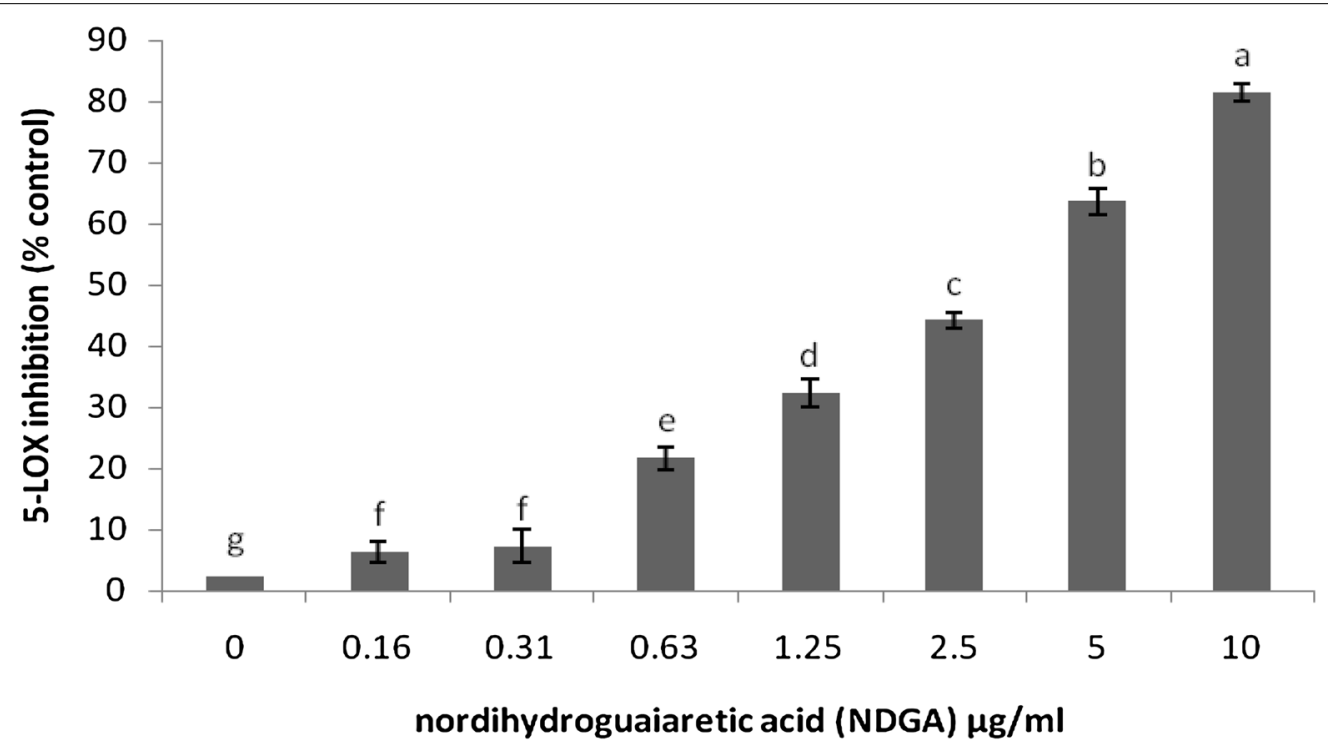

Fig. 5 Inhibition of soybean 5-LOX by NDGA as a positive control. The results are expressed as the mean \pm SEM $(n=3)$. The means with different letters were significantly different $(p<0.01)$

initiation of the inflammatory process associated with several diseases. Furthermore, CPE markedly attenuated the tested inflammatory signs by blocking the
TNF- $\alpha-\mathrm{NO}$, COX-II-PGE ${ }_{2}$ and 5-LOX-LT pathways. These findings provide a rationale for the application of CPE in clinical nutrition for the treatment of 
Table 2 Effect of CPE on the inhibition of pro-inflammatory mediators in RAW 246.7 macrophages

\begin{tabular}{lc}
\hline Inflammatory mediators & $\mathbf{I C}_{\mathbf{5 0}}(\boldsymbol{\mu} \mathbf{g} / \mathbf{m l})$ \\
\hline ROS & 425.95 \\
NO & 81.59 \\
5-LOX & 166.48 \\
TNF-a & 52.28 \\
PGE $_{2}$ & 27.57 \\
\hline
\end{tabular}

chronic diseases. In addition, the findings obtained in our in vitro study and other studies on human subjects and laboratory animals suggest that the improvement of the inflammatory state is a pivotal action of the dietary polyphenols derived from cocoa. However, further in vivo and in vitro studies, as well as human intervention trials, are required to clarify the mechanism through which cocoa polyphenols can prevent inflammation.

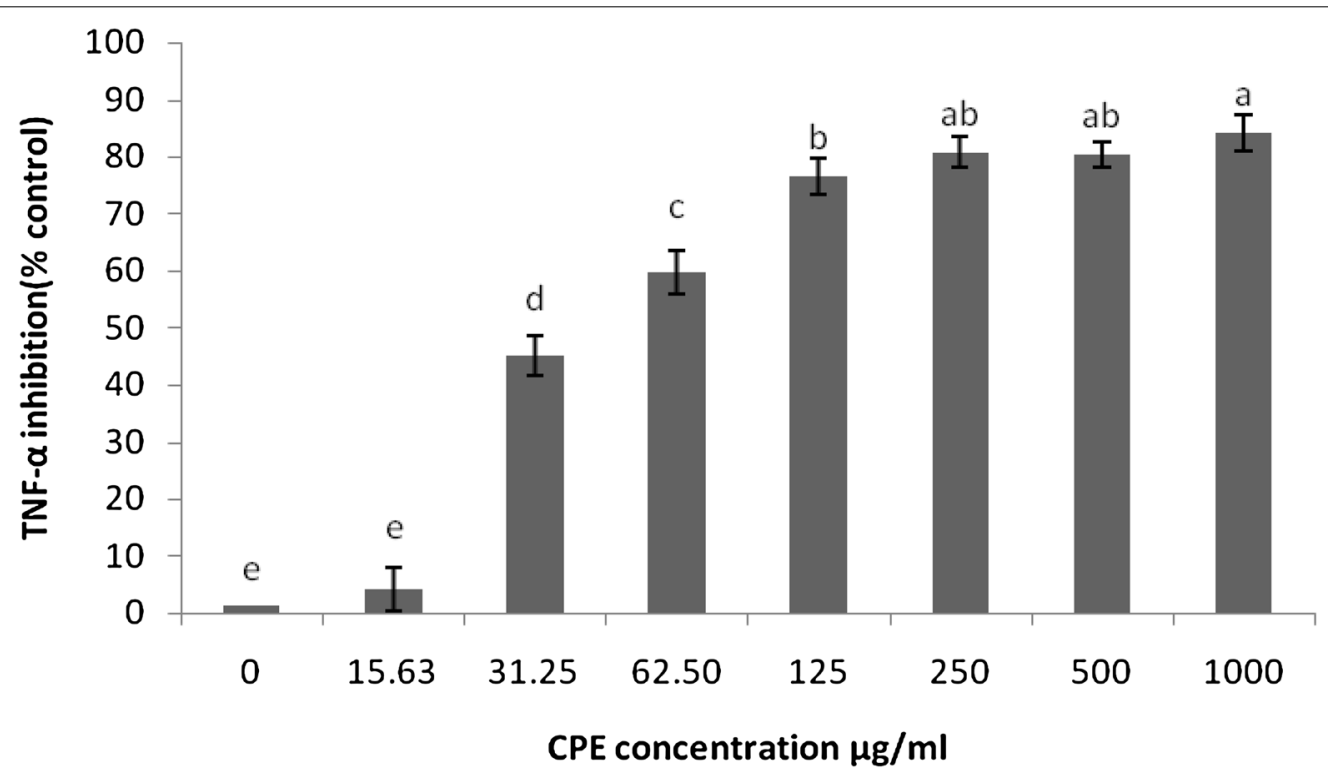

Fig. 6 Effects of CPE on the LPS-stimulated production of inflammatory mediators in RAW 264.7 cells. The TNF-a inhibition was determined using an ELISA kit. The results are expressed as the mean $\pm \operatorname{SEM}(n=3)$. The means with different letters were significantly different $(p<0.01$ or $p<0.05)$

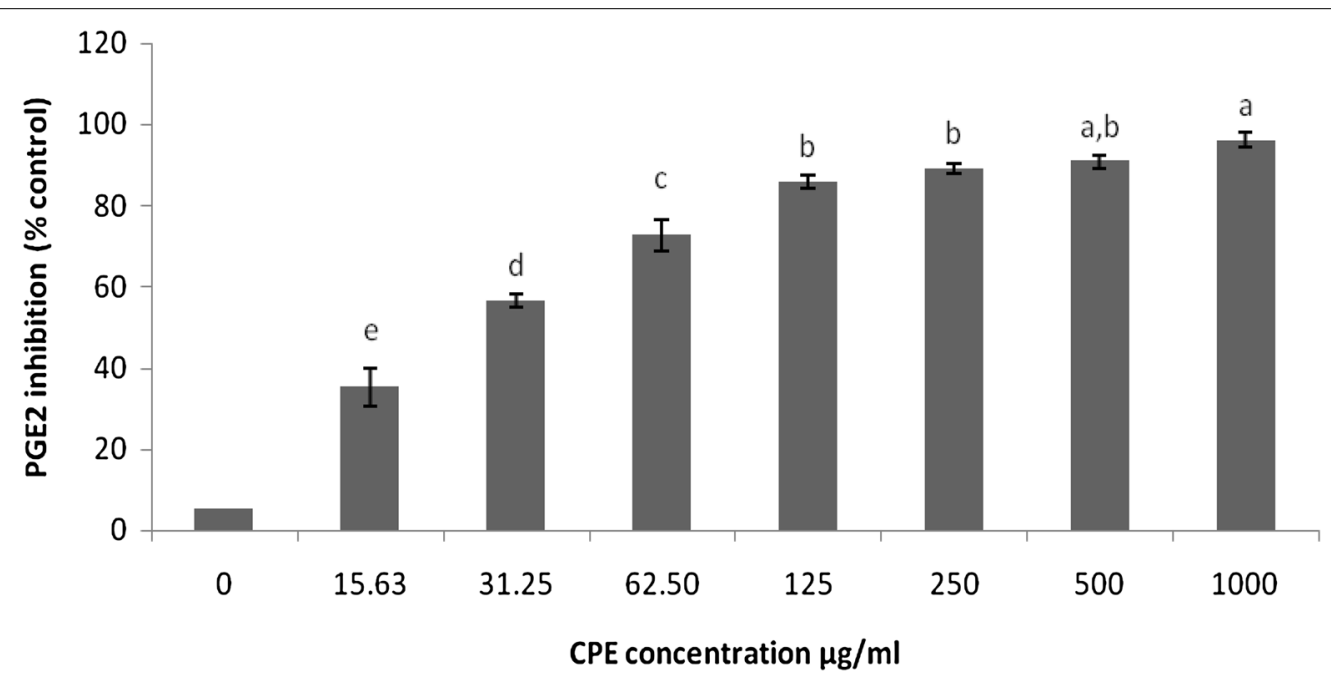

Fig. 7 Effects of CPE on the LPS-stimulated production of inflammatory mediators in RAW 264.7 cells. The PGE 2 inhibition was determined using an ELISA kit. The results are expressed as the mean \pm SEM $(n=3)$. The means with different letters were significantly different $(p<0.01$ or $p<0.05)$ 


\section{Abbreviations}

CPE: cocoa polyphenolic extract; COX-2: cyclooxygenase-2; IFN- $\gamma$ : interferongamma; IL-1 $\beta$ : interlukin-1 $\beta$; IL-6: interlukin-6; iNOS: nitric oxide synthase; LPS: lipopolysaccharide; 5-LOX: 5-lipoxygenase; MTT: 3-(4,5-dimethylthiazol-2-yl)2,5-diphenyl tetrazolium bromide; $\mathrm{NO}$ : nitric oxide; $\mathrm{PGE}_{2}$ : prostaglandin $\mathrm{E2}$; ROS: reactive oxygen specious; TNF-a: tumor necrosis factor-alpha.

\section{Authors' contributions}

YR and FA designed the research, performed the experiments, interpreted the data and wrote the manuscript. MA helped with the interpretation and analysis of the data. NME supervised, headed and financed the work and helped editing the manuscript. Al supervised the project, designed the research and interpreted the data. All authors read and approved the final manuscript.

\section{Author details}

${ }^{1}$ Department of Nutrition and Dietetics, Faculty of Medicine and Health Sciences, Universiti Putra Malaysia (UPM), 43400 Serdang, Selangor, Malaysia. ${ }^{2}$ Hematology Department, Faculty of Medicine and Health Sciences, University Hospital, Sana'a University, Sana'a, Yemen. ${ }^{3}$ Laboratory of Molecular Biomedicine, Institute of Bioscience, Universiti Putra Malaysia (UPM), 43400 Serdang, Selangor, Malaysia.

\section{Acknowledgements}

This work was supported by Research Grant Number 9315900. The authors would like to acknowledge the Faculty of Medicine and Health Sciences for the use of their laboratory facilities and the financial support. Additionally, we want to extend our thanks to the Institute of Bioscience for allowing us to use their facilities.

\section{Competing interests}

The authors declare that they have no competing interests.

Received: 5 January 2016 Accepted: 11 April 2016

Published online: 28 April 2016

\section{References}

Adams V, Nehrhoff B, Spate U, Linke A, Schulze PC et al (2002) Induction of iNOS expression in skeletal muscle by IL-1 beta and NFkappaB activation: an in vitro and in vivo study. Cardiovasc Res 54:95-104

Ali F, Ranneh Y, Ismail A, Esa NM (2013) Identification of phenolic compounds in polyphenols-rich extract of Malaysian cocoa powder using the HPLCUVESI-MS/MS and probing their antioxidant properties. J Food Sci Technol 62:2103-2111

Altavilla D, Squadrito F, Bitto A, Polito F, Burnett BP, Stefano V, Minutoli L (2009) Flavocoxid, a dual inhibitor of cyclooxygenase and 5-lipoxygenase, blunts pro-inflammatory phenotype activation in endotoxin-stimulated macrophages. Br J Pharm 157:1410-1418

Back M (2008) Inflammatory signaling through leukotriene receptors in atherosclerosis. Curr Atheroscler Rep 10:244-251

Bessis N, Boissier MC (2001) Novel pro-inflammatory interleukins: potential therapeutic targets in rheumatoid arthritis. Joint Bone Spine 68:477-481

Bi XL, Yang JY, Dong YX, Wang JM, Cui YH et al (2005) Resveratrol inhibits nitric oxide and TNF-a production by lipopolysaccharide-activated microglia. Int Immunopharmacol 5:185-193

Bisson JF, Guardia-Llorens MA, Hidalgo Rozan SP, Messaoudi M (2008) Protective effect of Acticoa powder, a cocoa polyphenolic extract, on prostate carcinogenesis in Wistar-Unilever rats. Eur J Cancer Prev 17:54-61

Brune K (2004) Safety of anti-inflammatory treatments-new ways of thinking. Rheumatology 43:116-120

Burdan F, Chalas A, Szumilo J (2006) Cyclooxygenase and prostanoids-biological implications. Postepy Hig Med Dosw 60:129-141

Celotti F, Laufer S (2001) Anti-inflammatory drugs: new multi target compounds to face an old problem. The dual inhibition concept. Pharmacol Res 43:429-436

Chai PC, Long LH, Halliwell B (2003) Contribution of hydrogen peroxide to the cytotoxicity of green tea and red wines. Biochem Biophys Res Commun 304:650-654
Datta K, Sinha S, Chattopadhyay P (2000) Reactive oxygen species in health and disease. Nat Med J India 13:304-310

Day R (2002) Adverse reactions to TNF-a inhibitors in rheumatoid arthritis. Lancet 359:540-541

Di RM, Lalenti A, lanaro A, Sautebin L (1996) Interaction between nitric oxide and cyclooxygenase pathways. Prostaglandins Leukot Essent Fatty Acids 54:229-238

Edwina N, Vishva MD (2013) Mitochondrial reactive oxygen species drive proinflammatory cytokine production. J Exp Med 208:417-420

Eigler A, Sinha B, Hartmann G, Endres S (1997) Taming TNF: strategies to restrain this proinflammatory cytokine. Immunonol Today 18:487-492

Ershler WB, Keller ET (2000) Age-associated increased interleukin-6 gene expression, late-life diseases and frailty. Ann Rev Med 51:245-270

Feldmann M, Brennan FM, Maini RN (1996) Role of cytokines in rheumatoid arthritis. Ann Rev Immunol 14:397-440

Frum Y, Viljoen AM (2006) In vitro 5-lipoxygenase activity of three indigenous South African aromatic plants used in traditional healing and the stereospecific activity of limonene in the 5-lipoxygenase assay. J Essent Oil Res 18:85-88

Hunskaar S, Hole K (1987) The formalin test in mice: dissociation between inflammatory non-inflammatory pain. Pain 30:103-114

Hussain SP, Hofseth L, Harris CC (2003) Radical causes of cancer. Nat Rev Cancer 3:276-285

Keen CL (2001) Chocolate: food as medicine/medicine as food. J Am Coll Nutr 20:436S-439S

Khanapure SP, Garvey DS, Janero DR, Letts LG (2007) Eicosanoids in inflammation: biosynthesis, pharmacology and therapeutic frontiers. Curr Top Med Chem 7:311-340

Kuehl FA Jr, Egan RW (1980) Prostaglandins, arachidonic acid and inflammation. Science 210:978-984

Kurosawa T, Itoh F, Nozaki A, Nakano Y, Katsuda SI et al (2005) Suppressive effect of cocoa powder on atherosclerosis in Kurosawa and Kusanagihypercholesterolemic rabbits. J Atheroscler Thromb 12:20-28

LeBel CP, Ali SF, McKee M, Bondy SC (1990) Organometal-induced increases in oxygen reactive species: the potential of 2-,7-dichlorofluorescein diacetate as index of neurotoxic damage. Toxicol Appl Pharmacol 104:17-24

Mac Micking J, Xie QW, Nathan C (1997) Nitric oxide and macrophage function. Annu Rev Immunol 15:323-350

Marletta MA, Yoon PS, lyengar R, Leaf CD, Wishnok JS (1998) Macrophage oxidation of L-arginine to nitrite and nitrate: nitric oxide is an intermediate. Biochemistry 27:8706-8711

Moncada S, Palmer RM, Higgs EA (1991) Nitric oxide: physiology, pathophysiology and pharmacology. Pharmacol Rev 43:109-142

Mukherjee D, Nissen SE, Topol EJ (2001) Risk of cardiovascular events associated with selective COX-2 inhibitors. JAMA 286:954-959

Naik E, Dixit VM (2011) Mitochondrial reactive oxygen species drive proinflammatory cytokine production. J Exp Med 208:417-420

Ono K, Takahashi T, Kamei M, Mato T, Hashizume S et al (2003) Effects of an aqueous extract of cocoa on nitric oxide production of macrophages activated by lipopolysaccharide and interferon-gamma. Nutrition 19:681-685

Pang L, Hoult JRS (1997) Cytotoxicity to macrophages of tetrandrine, an antisilicosis alkaloid, accompanied by an overproduction of prostaglandins. Biochem Pharmacol 53:773-782

Park YC, Gerald R, Claude S, Giuseppe V, Lester P (2000) Activity of monomeric, dimeric and trimeric flavonoids on NO production, TNF-K secretion and NF-UB-dependent gene expression in RAW 264.7 macrophages. FEBS Lett 465:93-97

Rainsford KD (1999) Profile and mechanisms of gastrointestinal and other side effects of nonsteroidal anti-inflammatory drugs (NSAIDs). Am J Med 107:27S-36S

Reuter S, Gupta SC, Chaturvedi MM, Aggarwal BB (2010) Oxidative stress, inflammation and cancer: how are they linked? Free Radical Biol Med 49:1603-1616

Rodriguez-Ramiro I, Sonia R, Laura B, Luis G, Martin MA (2011) Procyanidin B2 and a cocoa polyphenolic extract inhibit acrylamide-induced apoptosis in human Caco-2 cells by preventing oxidative stress and activation of JNK pathway. J Nutr Biochem 22:1186-1194 
Ruzaidi A, Amin I, Nawalyah AG, Hamid M, Faizul HA (2005) The effect of Malaysian cocoa extract on glucose levels and lipid profiles in diabetic rats. J Ethnopharmacol 98:55-60

Salmon JA, Higgs GA (2012) Prostaglandins and leukotrienes as inflammatory mediators. Br Med Bull 43:285-296

Schinella G, Mosca S, Cienfuegos-Jovellanos E, Pasamar MA, Muguerza B, Ramon D, Rios JL (2010) Anti-oxidant properties of polyphenol-rich cocoa products industrially processed. Food Res Int 43:1614-1623

Schramm DD, Wang JF, Holt RR, Ensunsa JL et al (2001) Chocolate procyanidins decrease the leukotriene-prostacyclin ratio in humans and human aortic endothelial cells. Am J Clin Nutr 73:36-40

Seligson FH, Krummel DA, Apgar JL (1994) Patterns of chocolate consumption. Am J Clin Nutr 601:1060S-1064S

Sies H, Schewe T, Heiss C, Kelm M (2005) Cocoa polyphenols and inflammatory mediators. Am J Clin Nutr 81(suppl):304S-312S

Vane JR, Mitchell JA, Appleton I, Tomlinson A, Bishop-Bailey D, Croxtall J, Willoughby DA (1994) Inducible isoforms of cyclooxygenase and nitric-oxide synthase in inflammation. Proc Natl Acad Sci 91:2046-2050
Wolf AM, Wolf D, Rumpold H, Ludwiczek S, Enrich B et al (2005) The kinase inhibitor Imatinib Mesylate inhibits TNF-a; production in vitro and prevents TNF-dependent acute hepatic inflammation. Proc Nat Acad Sci 102:13622-13627

Yoon S, Lee Y, Park SK, Kim HC, Bae H et al (2009) Anti-inflammatory effects of Scutellaria baicalensis water extract on LPS-activated RAW264.7 macrophages. J Ethnopharmacol 125:286-290

Yun KJ, Koh DJ, Kim SH, Park SJ, Ryu JH et al (2008) Anti-inflammatory effects of sinapic acid through the suppression of inducible nitric oxide synthase, cyclooxygase-2 and proinflammatory cytokines expressions via nuclear factor-KB inactivation. J Agric Food Chem 56:10265-10272

Zhang L, Cheng A, Liu H, Wang Y, Du G (2010) Antioxidant, anti-inflammatory and anti-influenza properties of compounds from Chaenomeles species. Molecules 15:8507-8517

\section{Submit your manuscript to a SpringerOpen ${ }^{\odot}$ journal and benefit from:}

- Convenient online submission

- Rigorous peer review

- Immediate publication on acceptance

- Open access: articles freely available online

- High visibility within the field

- Retaining the copyright to your article 